\title{
Disaster, Disruption to Family Life, and Intimate Partner Violence: The Case of the 2010 Earthquake in Haiti
}

\author{
Abigail Weitzman, ${ }^{a}$ Julia Andrea Behrman ${ }^{b}$
}

a) University of Michigan; b) New York University

\begin{abstract}
Natural disasters have inherently social dimensions because they exacerbate preexisting inequalities and disrupt social norms and institutions. Despite a growing interest in the sociological aspects of disasters, few studies have quantitatively explored how disasters alter intrahousehold family dynamics. In this article, we develop and test a conceptual framework that explicates how natural disasters affect an important component of family life: intimate partner violence (IPV). We combine two waves of geocoded Demographic and Health Surveys data, collected before and after the 2010 earthquake in Haiti, with spatial data on variation in the earthquake's destruction. Our findings indicate that exposure to earthquake devastation increased the probability of both physical and sexual IPV one to two years following the disaster. These increases were accompanied by substantial changes in family functioning, the household economy, and women's access to their social networks. Select household-level experiences during and after the earthquake, such as displacement, were also positively associated with IPV. These findings provide new insights into the multidimensional effects of disasters on family life and have important theoretical and policy implications that extend beyond the particular case of Haiti.
\end{abstract}

Keywords: intimate partner violence; natural disasters; family

Citation: Weitzman, Abigail and Julia Andrea Behrman. 2016. "Disaster, Disruption to Family Life, and Intimate Partner Violence: The Case of the 2010 ." Sociological Science 3: 167-189.

Received: December 3, 2015

Accepted: December 31, 2015

Published: March 7, 2016

Editor(s): Jesper Sørensen, Olav Sorenson

DOI: $10.15195 / \mathrm{v3} . \mathrm{ag}$

Copyright: (C) 2016 The Author(s). This open-access article has been published under a Creative Commons Attribution License, which allows unrestricted use, distribution and reproduction, in any form, as long as the original author and source have been credited. (C) (i)
ATURAL disasters have inherently social dimensions because they exacerbate preexisting inequalities and disrupt social norms and longstanding institutions (Klinenberg 2002). Sociological scholarship has explored the effects of disasters on a range of social outcomes, including human capital development (Bruckner and Nobles 2013; Fuller 2014), mental health (Frankenberg et al. 2008), and demographic processes (Frankenberg et al. 2013). Despite a growing interest in the sociological aspects of disasters, few studies have quantitatively explored how disasters alter intrahousehold family dynamics. In this article, we focus on the effect of natural disasters on a component of family life that threatens to undermine women's well-being and economic, human, and social capital-intimate partner violence (IPV) (Beydoun et al. 2012; Crowne et al. 2011). Understanding whether and how IPV becomes elevated after a disaster is a crucial step toward designing policies that better protect women against violence in times of crisis. Moreover, from a theoretical perspective, understanding the effects of disasters on family functioning and violence is essential to understanding how disasters affect household inequality and gender stratification more broadly.

In this study, we integrate diverse theoretical perspectives on IPV to develop a sociological framework that explicates how natural disasters can exacerbate household violence, particularly against women. Our approach links postdisaster 
IPV to broader, multidimensional effects of disasters on family functioning. To test our framework, we compare changes in IPV and theoretically related outcomes in the most affected regions of Haiti to changes in regions that were only moderately affected, a strategy commonly known as difference-in-difference (DID). Under normal circumstances, DID strategies use changes within unaffected populations to make inferences about what would have happened in the absence of exposure to disasters (or other treatments). In the case of the 2010 earthquake, such inferences are complicated by postdisaster migration and by the fact that no one region of Haiti went entirely unaffected. We address these concerns by demonstrating that our results are robust to a number of alternative specifications, including limiting our analysis to nonmigrants and employing different counterfactuals. As a final analytic component, we use a unique module of the 2012 Demographic and Health Surveys (DHS) to investigate how specific earthquake-related experiences, such as displacement, mediate the effects of earthquake devastation on IPV. This layered analysis provides the first comprehensive investigation into how a catastrophic disaster can disrupt family life in ways that ultimately affect the risk of IPV-an outcome with important implications for women's economic and physical wellbeing and for household gender stratification.

\section{Theoretical Pathways between Disasters and Intimate Partner Violence}

Disasters may increase the threat of IPV for several reasons. First, from a social psychological perspective, disasters increase trauma and uncertainty (Frankenberg et al. 2008), which may lead to heightened relationship volatility and substance use (Powell and Holleran Steiker 2012)—outcomes that are positively associated with IPV (Gage 2005). Similarly, a prolonged sense of uncontrollability can increase an individual's desire to control the individual's immediate environment (Shapiro, Schwartz, and Astin 1996), potentially spilling over to affect men's use of violence as a control tactic. These effects of trauma and uncertainty are likely to be most pronounced among families that experience a high level of destruction, for example, losing a family member or experiencing property damage (Harville et al. 2011; Larrance, Anastario, and Lawry 2007).

Second, disasters may contribute to IPV by negatively impacting men's and women's personal resources and the household economy. Disaster-related reductions in men's material resources may lead to the increased use of force among men who view violence as an acceptable tool of persuasion in the absence of alternative resources (Goode 1971). Reductions to women's personal resource bases may prohibit women from living on their own and increase their dependency on partners (Kalmuss and Straus 1982). At the household level, changes in income may generate financial stress, contributing to a higher degree of conflict (Fox et al. 2002).

Third, women may have more limited access to friends and extended family in the aftermath of a disaster. This could occur if disasters heighten men's desire to control their partners' whereabouts, if negative shocks to the household economy 
prevent women from being able to afford childcare or transportation costs, or if disasters result in the death or displacement of family and friends.

Fourth, disasters may affect residential patterns in a way that increases women's risk of violence. For example, unmarried couples may be more likely to live together after a disaster if one partner lost a home. Meanwhile, unhappily married or cohabiting couples may continue living together after a disaster if changes in their financial situation prohibit either partner from leaving the household.

Fifth, at an institutional level, disasters can undercut the ability of intervening public institutions to protect vulnerable populations (Fothergill 1999), thereby reducing women's options for leaving abusive relationships.

\section{Measuring the Effects of Disasters on Intimate Partner Violence}

Despite the many reasons to believe that women become more susceptible to violence in the aftermath of disaster, past efforts to estimate this phenomenon have been hampered by several types of data limitations. For instance, secondhand accounts from nongovernmental organizations working in disaster-affected areas (Fulu 2007; MacDonald 2005) are unable to distinguish between violence that stems from a disaster and violence that is made more visible by changes in the physical environment. Even scholarly postdisaster data collection on IPV is often limited to the recruitment of disaster-affected populations (Clemens et al. 1999; Harville et al. 2011; Larrance et al. 2007). Though such data help to identify which disaster-related experiences, such as property damage, are associated with an elevated risk of IPV (Harville et al. 2011), they are unable to determine whether women experiencing postdisaster violence are also at greater risk predisaster.

Relatedly, most sources of data on predisaster IPV are hospital records (Clemens et al. 1999) and police reports (Siegel, Bourque, and Shoaf 1999), which are notoriously subject to reporting bias (Palermo, Bleck, and Peterman 2014). Such bias may become particularly problematic if hospitals and police forces are also negatively impacted by a disaster. Moreover, observing changes within an affected population (Clemens et al. 1999) yields estimates that are biased by any changes that would have occurred even in the absence of disaster.

\section{Poverty and the 2010 Earthquake in Haiti}

Haiti is the poorest country in the Western hemisphere (World Bank 2014). Approximately 70 percent of the population lives on less than $\$ 2$ a day (Farmer 2011:60); less than 34 percent has regular access to electricity (World Bank 2014); and only 62 percent has access to piped water or water from a well, making it one of the most water-insecure countries in the world (World Bank 2014). This extreme level of poverty has historically exacerbated Haiti's vulnerability to disasters (Farmer 2011; Katz 2013).

On January 12, 2010, an earthquake of 7.0 magnitude on the Richter scale struck 25 kilometers outside of Haiti's capital, Port-au-Prince. The location of the 
epicenter, combined with the poor quality of preexisting physical infrastructures, led to catastrophic loss. Between 50,000 and 110,000 people died during the disaster (Doocy, Cherewick, and Kirsch 2013), the overwhelming majority of whom were children aged younger than 18 years (Kolbe 2010) and adults aged older than 50 years (Doocy et al. 2013). Another 1.2 million people became displaced (Kolbe 2010), though most displaced persons remained close to their original homes or returned within a year ( $\mathrm{Lu}$ 2012). Others fled the country, mainly to the Dominican Republic, as few were able to enter the United States or Canada (Murray and Williamson 2011). Though no exact estimates of postearthquake immigration to the Dominican Republic exist, it is believed that at least some displaced persons returned to Haiti within two years (Ferris 2014). ${ }^{1}$

Ten months after the earthquake, a cholera epidemic broke out in the departments of Artibonite and Centre. This epidemic was a direct result of the disasterintroduced to Haiti by a United Nations relief worker from Nepal (Farmer 2011). The poor sanitation system and extreme water insecurity in Haiti, both made worse by the earthquake, led the waterborne disease to spread quickly throughout the entire country (Farmer 2011; Piarroux et al. 2011). Cholera- and earthquake-related mortality and migration present important implications for our understanding of the effects of the earthquake on IPV and related postdisaster changes in family life.

\section{Intimate Partner Violence in Haiti}

Prior to the disaster, 14 percent of women reported a lifetime prevalence of physical IPV (Cayemittes et al. 2007) - a rate comparable to that of other Caribbean countries, such as the Dominican Republic and Jamaica (Bott et al. 2012). However, the lifetime prevalence of sexual IPV among Haitian women before the earthquake-11 percentwas three times the rate of sexual IPV found in neighboring Caribbean countries (Bott et al. 2012; Cayemittes et al. 2007).

Despite Haiti having no laws against IPV, the rate of both physical and sexual IPV fell during the early 2000s (Cayemittes et al. 2001; Cayemittes et al. 2007). The same is true for a wide range of countries in the Western hemisphere, including countries as diverse as the United States and the Dominican Republic (Achecar et al. 2003; Achecar et al. 2008; Catalano 2012). These changes in the early 2000s may be attributable to a number of factors, including global and local campaigns to end violence against women (Pierotti 2013), initiated by nongovernmental organizations and lawmakers alike. However, in the Haitian case, this decline cannot be attributed to changes in IPV laws, as no IPV laws were introduced in this period. Furthermore, declines are not likely attributable to changes in the economic environment, as men's and women's labor force participation rates and the national poverty level both remained low during the early 2000s (World Bank 2014). The preearthquake downward trend in IPV also presents important implications for contextualizing postearthquake changes in IPV. 


\section{Data and Methods}

\section{Sample}

We use two nationally representative data sets from the DHS collected in Haiti. The first, from 2005 and 2006, represents our unexposed control sample. The second, from 2012, represents our treatment sample, collected two years after the earthquake. Together, these repeated cross sections facilitate a comparison of differences within and between populations before and after their exposure to the earthquake. In both waves, the DHS had a 99 percent response rate, suggesting that the earthquake did not impede data collection.

The DHS offer several unique benefits to this study. First, because DHS data in Haiti are geocoded, we are able to match the geographic location of survey clusters with spatial data on the intensity of the 2010 earthquake (Figure 1 ). ${ }^{2}$ Second, preand postearthquake surveys asked the same questions about IPV. Third, the 2012 DHS included a special module on earthquake-related experiences, allowing us to investigate which postdisaster circumstances are most strongly associated with IPV.

IPV questions were asked to one random woman per household, and only if privacy was secured. In both waves, 99 percent of invited respondents agreed to participate in the module. By necessity, we limit our sample to these respondents. We also limit our sample to respondents who were not widowed at the time of survey because some of these women may have become widowed as a result of the earthquake ( $n=242,<3 \%$ ). This yields a final sample of 2,535 observations from 2005-6 and 6,287 observations from 2012.

\section{Outcomes}

Both DHS IPV modules asked respondents seven questions about physical forms of IPV occurring in the year before survey. These included "Does your husband ever slap you?" "Twist your arm or pull your hair?" "Push you, shake you, or throw something at you?" "Punch you with a fist or something that could hurt you?" "Kick you, drag you, or beat you up?" "Try to choke you or burn you on purpose?" and "Threaten or attack you with a knife, gun, or any other weapon?" When a respondent answered yes, the interviewer asked whether this form of violence occurred "sometimes," "often," or "not at all" within the last 12 months. Relying on information about the occurrence and frequency of violence, we create two measures of physical IPV. Any physical violence is coded 1 if a respondent reported that she experienced at least one type of violence within the last year and 0 if she reported no violence within that time. Physical violence frequency is coded 0 if a respondent reported that violence had not occurred within the last year, 1 if at least one form of violence occurred "sometimes" but none occurred "often," and 2 if any form of violence occurred "often."

The IPV modules also asked two questions pertaining to sexual violence. These included whether the respondent's partner ever "forced" her to have sex and whether her partner had ever forced her to "perform other sexual acts." Respondents who provided an affirmative answer to either question were then asked, "Did this happen sometimes, often, or not at all in the last 12 months?" Based 
on these questions, we derive two measures of sexual violence-its occurrence at all in the prior year and its categorical frequency. Any sexual violence is coded 1 when a respondent reported that her partner forced her to have sex or to perform other sexual acts within the preceding year and 0 when he did not. ${ }^{3}$ Sexual violence frequency is coded in the same way as physical violence frequency.

\section{Pathways}

Beyond IPV, we investigate whether earthquake exposure affected four other dimensions of family life.

Coping behaviors. We assess a partner's coping behaviors with a measure of his controlling behaviors and with a measure of his alcohol consumption. Respondents in the DHS were asked five questions about their partners' controlling behaviors. These included whether one's partner becomes jealous when she talks with other men, accuses her of being unfaithful, does not permit her to visit friends, does not permit her to visit family, and insists on knowing where she is. We create a count variable for partner's controlling behaviors, ranging from 0 to $5(\alpha=0.77)$. One hundred sixty-seven respondents reported that they did not know if their partner gets jealous, and 21 reported that they did not know about various other controlling behaviors. These respondents are excluded from our measure. Omitting information about partner's jealousy (and thus including the 167 respondents who "do not know") yields similar results in terms of magnitude, significance, and direction.

Partner consumes alcohol is coded 1 if the respondent said her partner drinks alcohol and 0 if she said he does not. No additional information on partners' alcohol consumption was collected in both waves.

Household economy. To assess changes to the household economy, we measure a respondent's employment, her partner's employment, and body mass index (BMI; a proxy for extreme poverty). We derive respondents' employment status from the question "Have you done any work in the last 12 months?" This question was intended to capture formal as well as informal employment. We code women who reported performing any work for compensation in the last 12 months as 1 and women who did not as 0 .

Information on whether partners are "currently working" was only collected among married and cohabiting respondents $(n=3,658)$. We code this variable 1 for yes and 0 for no.

Underweight is coded according to guidelines from the Centers for Disease Control, where respondents with a BMI of less than 18.5 are coded 1 and respondents above this threshold are coded 0 . BMI is calculated based on height and weight measurements that were taken by the DHS interviewer. We rely on being underweight as a more concrete indicator of extreme poverty and financial duress because household wealth in the DHS is measured relative to all other households in the survey.

Residential patterns. Coresidence with partner is measured with a dichotomous variable, coded 1 for respondents who were cohabiting or who were married and 
living with a husband and 0 for respondents who were married or coupled but not coresiding or who were divorced and not recoupled.

Access to social networks. We assess respondents' access to their support network with answers to the question "Who usually decides on visits to family or friends?" Respondents who reported that they alone or they and their partner decide together are coded 1; respondents who reported that their partner alone or someone else decides are coded 0 . As a sensitivity test, we also run models predicting two related outcomes-whether one's partner permits her to visit with family $(1 / 0)$ and whether he permits her to visit with friends $(1 / 0)$. We report on these outcomes in the main text but do not include the results in our tables, as they are already included in our control issues scale.

\section{Treatment}

We exploit the random occurrence and variation in the intensity of the 2010 earthquake's destruction in Haiti. To do so, we combine information about the timing of survey data collection (pre- and postdisaster) and the level of earthquake intensity. We focus on state-level variation in intensity because DHS survey clusters differed from one wave to the next, but when pooled and weighted, state-level data remain representative. Moreover, by relying on state-level variation, rather than on districtlevel variation, we reduce bias introduced by migration. In other words, as long as respondents who migrated remained within their state's boundaries, their assigned intensity level will be accurate.

To begin, we overlay the geocoordinates of 2012 DHS survey clusters onto a map of the earthquake's intensity, provided by the U.S. Geological Survey (USGS) (Figure 1). The USGS assigns intensity scores based on the Mercalli scale, an internationally recognized scale that ranges from 1 (undetectable) to 12 (complete destruction). Using the Mercalli scores observed among 2012 survey clusters, we calculate state averages (Supplementary Table 1) and then create a three-category variable defined as "moderate" $(D=0)$ for an average score $<5$, "severe" $(D=1)$ for an average score between 5 and 7 , and "devastating" $(D=2)$ for an average score $>7$.

To capture temporal exposure, or whether a respondent was observed after the earthquake $(t=1)$, we include a dummy indicating that the respondent's survey year was postdisaster, 2012. Respondents surveyed in 2005-6 constitute the unexposed control group $(t=0)$.

To estimate the DID between states pre- and postearthquake, we create an interaction term between intensity $(D)$ and temporal exposure $(t)$. A positive interaction would suggest that the probability of IPV became higher than it would have been in the absence of devastating earthquake destruction. A negative interaction would suggest the opposite.

Additional indicators of earthquake experience. Our analysis of the effects of earthquake intensity is complemented by an investigation into variation across postearthquake experiences. These experiences include ever residing in a displacement camp (self-reported by respondents), physical trauma to a household member, damage or destruction to one's house, and cholera contamination of a household member. 


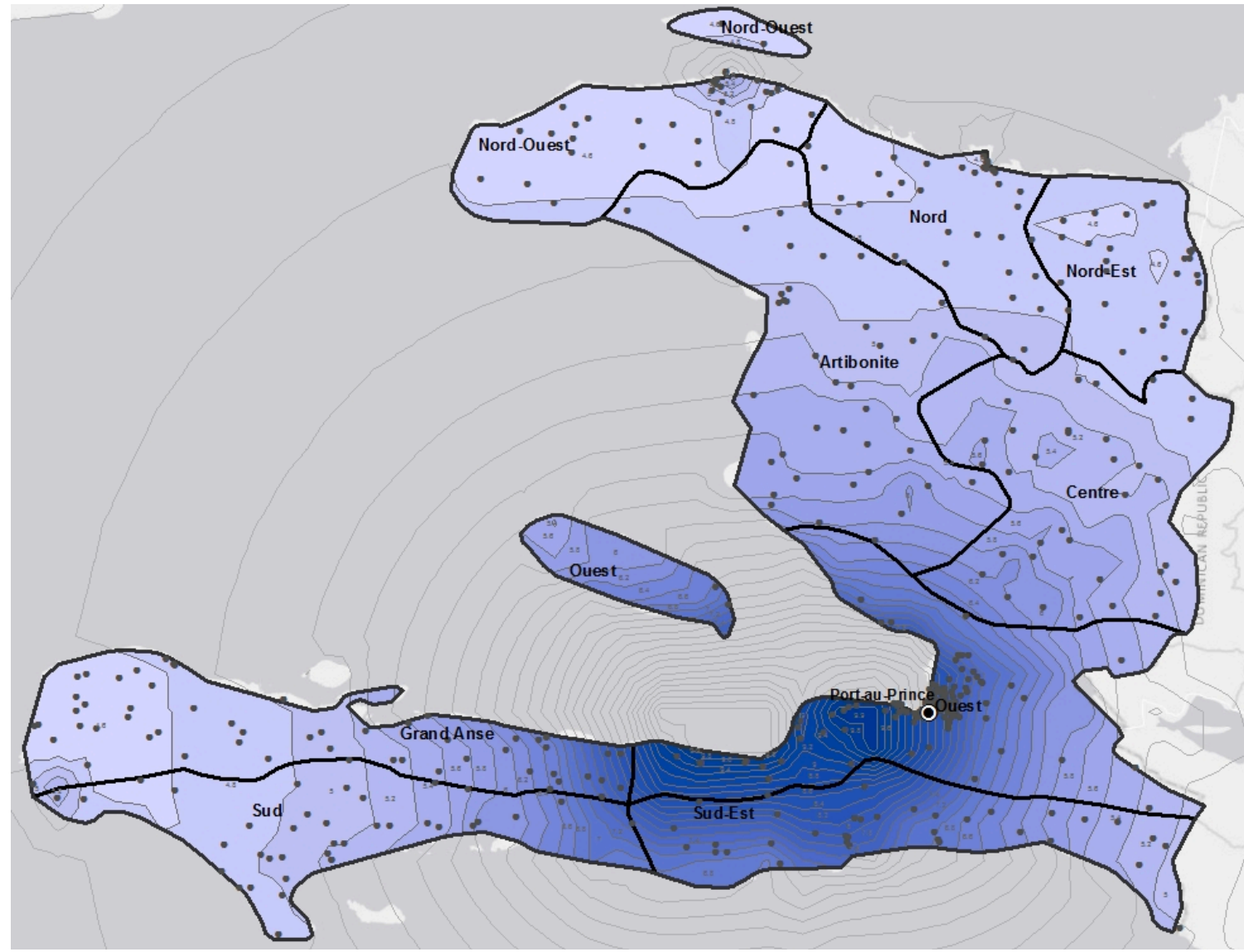

Figure 1: Map of 2012 DHS clusters and 2010 earthquake intensity. This map was created using 2010 U.S. Geological Survey data. The darker the shading, the higher the Mercalli score of earthquake intensity (ranging 4.6-9.8). The gray dots indicate 2012 DHS clusters, jittered within 0 and 2 kilometers of origin in urban areas and within 0 and 5 kilometers in rural areas. One percent of rural clusters are displaced between 0 and 10 kilometers.

The latter three experiences are reported by the head of the household and linked to respondents using household identification numbers.

Lived in a displacement camp is coded 1 if a respondent reported that she lived in a camp after the earthquake and 0 if she did not. Physical trauma to household members is coded 2, "member killed," if someone in the respondent's household died as a result of the disaster; 1 , "member wounded," if someone was wounded but no one was killed; and 0, "no one hurt," if all household members survived the earthquake unscathed. House condition is based on the original questionnaire and categorized as 0 for "no damage," 1 for "damaged," and 2 for "destroyed." Finally, if someone in the household was stricken with cholera in the months after the earthquake, the respondent is coded 1 for yes; if not, she is coded 0 for no. ${ }^{4}$

Controls. Our DID models include only covariates that are not correlated with earthquake intensity or earthquake-related experiences because these may be endogenous to the outcomes of interest (Gelman and Hill 2007:188). These include 
the respondent's age and a dummy indicating whether the respondent reported that her father abused her mother. We also control for the respondent's highest level of education attended (even if not completed): none, primary, and secondary or higher. ${ }^{5}$ Doing so should not bias our estimates because the youngest respondents are 15 years of age, and only 5 percent of the 2012 sample attended college (univariate analysis not shown). In other words, the earthquake should not have affected the highest level of education completed by respondents before the survey because most respondents should have arrived at their highest level of education before the earthquake.

In our analysis of the associations between earthquake-related experiences and IPV, we include a larger set of controls, each of which has formerly been shown to affect IPV in Haiti (Gage 2005). These include our aforementioned controls as well as respondents' number of surviving children (range 0-13); whether their partner consumes alcohol; and their marital status at survey, defined as married, cohabiting, or divorced or separated.

\section{Methodological Strategy}

We begin with a DID analysis that exploits geographic variation in the intensity of the 2010 earthquake and temporal variation in survey data collection. Respondents in 2012 are assigned to one of three different levels of treatment $(D)$, according to their state's average Mercalli score. Respondents in 2005-6 are assigned the corresponding placebo-the treatment level reflecting their state's average Mercalli score from the 2010 earthquake. Our "first-level" differences are a comparison of IPV across women in moderately, severely, and devastatingly affected areas at both waves and a comparison of pre- and postearthquake $(t)$ differences within each of the treatment levels. Our DID is a comparison of changes in the most devastatingly and severely affected areas $(D=2$ and $D=1$, respectively) with changes in the least affected ones (Equation (1)):

$$
Y=\beta_{0}+\beta_{1} D_{1}+\beta_{2} D_{2}+\beta_{3} t+\left(\beta_{4} D_{1} * t\right)+\left(\beta_{5} D_{2} * t\right)+\cdots \beta_{k} X_{k}+\gamma_{i} .
$$

One assumption of DID analyses is that the exposed and unexposed (or less exposed) samples are comparable. This is challenging in the case of the 2010 earthquake because the disaster disproportionately affected Haiti's capital. We thus check for preexisting differences across regions on a number of observable characteristics and find that the distributions of important observable traits, including history of family violence, partner's controlling behaviors, spousal coresidence, and employment levels, do not significantly differ between the moderate and devastated subsamples (Supplementary Table 2). However, the devastated subsample was more educated and less poor than the moderate subsample before the earthquake. Given that our estimates could be biased by these differences, we test the robustness of our findings to a series of alternative counterfactuals. In one, we estimate DIDs where the counterfactual is the second most economically developed state in Haiti, Nord, which was only moderately affected by the earthquake (Supplementary Table 3). In the other, we estimate DIDs where the counterfactual is the preexisting withinregion trend between 2000 and 2005-6 (Supplementary Table 4). Both alternatives 
yield similar results to our main models, underscoring the robustness of our results to different counterfactuals. Moreover, as an additional sensitivity test, we estimate models that include a three-way interaction term between survey year, earthquake intensity, and educational level. These models confirm that the effects of exposure to earthquake devastation do not vary significantly by respondents' education, a proxy for their socioeconomic status (Supplementary Table 6).

Another assumption of DID analyses is that the composition of exposed and unexposed samples remains similar from one wave to the next. We test for this with $t$-tests comparing proportions and means of sample characteristics from the 2005-6 and 2012 waves for each level of treatment (Table ??). The results suggest that the demographic characteristics of our sample that are unrelated to the earthquake, such as age and height, largely remained unchanged. However, average height increased by 0.8 centimeters in the devastated sample, and secondary education increased everywhere (Table ??). These changes may reflect cohort differences or differences in postearthquake population composition. As a second test, we conduct within-treatment-level cohort comparisons of height and education across survey waves. We focus on these two traits because they should remain fixed in adulthood, meaning that systematic differences should only occur as a result of selective migration or mortality. Our comparison reveals no changes in the distribution of education and no systematic changes in the distribution of height between the 2005-6 and the 2012 samples (available on request). ${ }^{6}$ This stability is not surprising given that most earthquake fatalities were children and adults aged older than 50 years (Doocy et al. 2013; Kolbe 2010) and given that most people who migrated after the earthquake stayed within their state's boundaries and returned within one year (Lu 2012).

A related, third assumption of DID estimation strategies is that there is no contamination across exposed and unexposed samples (via migration). In addition to the cohort comparisons we conduct, which provide little evidence of contamination, we further rule out possible violations of this assumption by rerunning our DID analysis restricting the 2012 sample to respondents who remained in their preearthquake homes and find the results to be nearly identical to those of our main analysis (Supplementary Table 3).

We use linear probability models to estimate DIDs in the probabilities of physical and sexual violence and multinomial logistic regression to estimate DIDs in the probabilities of violence occurring "sometimes" or "often." In the latter models, we transform the original results (odds ratios) into marginal effects. We then use the same DID strategy to estimate the effects of the earthquake on outcomes that could provide insight into underlying mechanisms, using a linear specification for binary outcomes and Poisson for count outcomes. To determine the extent to which our proposed mechanisms mediate the effects of earthquake devastation on IPV, we return to our DID analysis of IPV and adjust for pathway indicators that we find were significantly affected by the earthquake.

In the last portion of our analysis, we focus on respondents surveyed in 2012 and estimate the effects of various earthquake-related experiences (e.g., displacement) on the probability of experiencing IPV within the preceding year (and thus between one and two years after the earthquake). These analyses are conducted with linear 
probability models and adjust for the same controls as the primary DID analyses as well as for marital status, number of living partners, and whether the respondent's partner drinks alcohol.

All models are run with DHS population weights. To account for the correlation of observations within state-years, we cluster our standard errors by state-year.

\section{Multivariate Results}

\section{Results of Difference-in-Difference Analyses Observing the Effects of 2010 Earthquake on Intimate Partner Violence}

We evaluate whether and how exposure to the 2010 earthquake increased IPV in Haiti. We therefore focus our attention solely on the regression parameters of interest: those that measure first-level differences across space and time and those that measure DIDs capturing the effects of earthquake exposure (Table 2). The latter are captured by interaction effects, which express the multiplicative effect of earthquake exposure (by intensity level) on the percentage point change in the probability of IPV and IPV frequency. These interaction effects are relative to a baseline counterfactual estimated over the same time period among respondents living in the areas of Haiti that were only moderately affected by the earthquake.

Prior to the disaster, physical IPV was 3 percentage points higher in the devastated than in the moderately affected regions of Haiti (model I). Between 2005-6 and 2012, the probability of any physical violence remained unchanged in the moderately affected areas of Haiti (model I), although the probability that physical violence occurred "sometimes" fell by 2 percentage points in these areas (model II). Meanwhile, the probability of any physical IPV increased by 0.4 percentage points in the devastated region (model I). Using trends in the moderately affected region as a counterfactual suggests that earthquake devastation increased the probability of physical IPV by 1.4 percentage points but did not affect the frequency of physical violence (model II).

No significant differences in the prevalence of sexual IPV existed across the three subsamples before the earthquake (model III, Table 2), though the probability that sexual violence occurred "sometimes" was 2 percentage points higher and the probability that sexual violence occurred "often" was 2 percentage points lower in devastated regions than in moderate ones. Between 2005-6 and 2012, sexual IPV decreased by 5 percentage points in the moderately affected regions. During this time, the probabilities that sexual violence occurred "sometimes" and "often" each fell by 3 percentage points in moderate areas (model IV). In the devastated region, the probability of any sexual IPV and the probability of sexual IPV occurring "often" only decreased by 1 percentage point each between 2005-6 and 2012 (models III and IV). Comparing these changes to the changes observed in the moderately affected region suggests that devastation increased the probability of sexual IPV by 4 percentage points and the probability that such violence occurred "often" by 3 percentage points. 
Table 1: Descriptive Statistics by Survey Year: Mean (Standard Error)

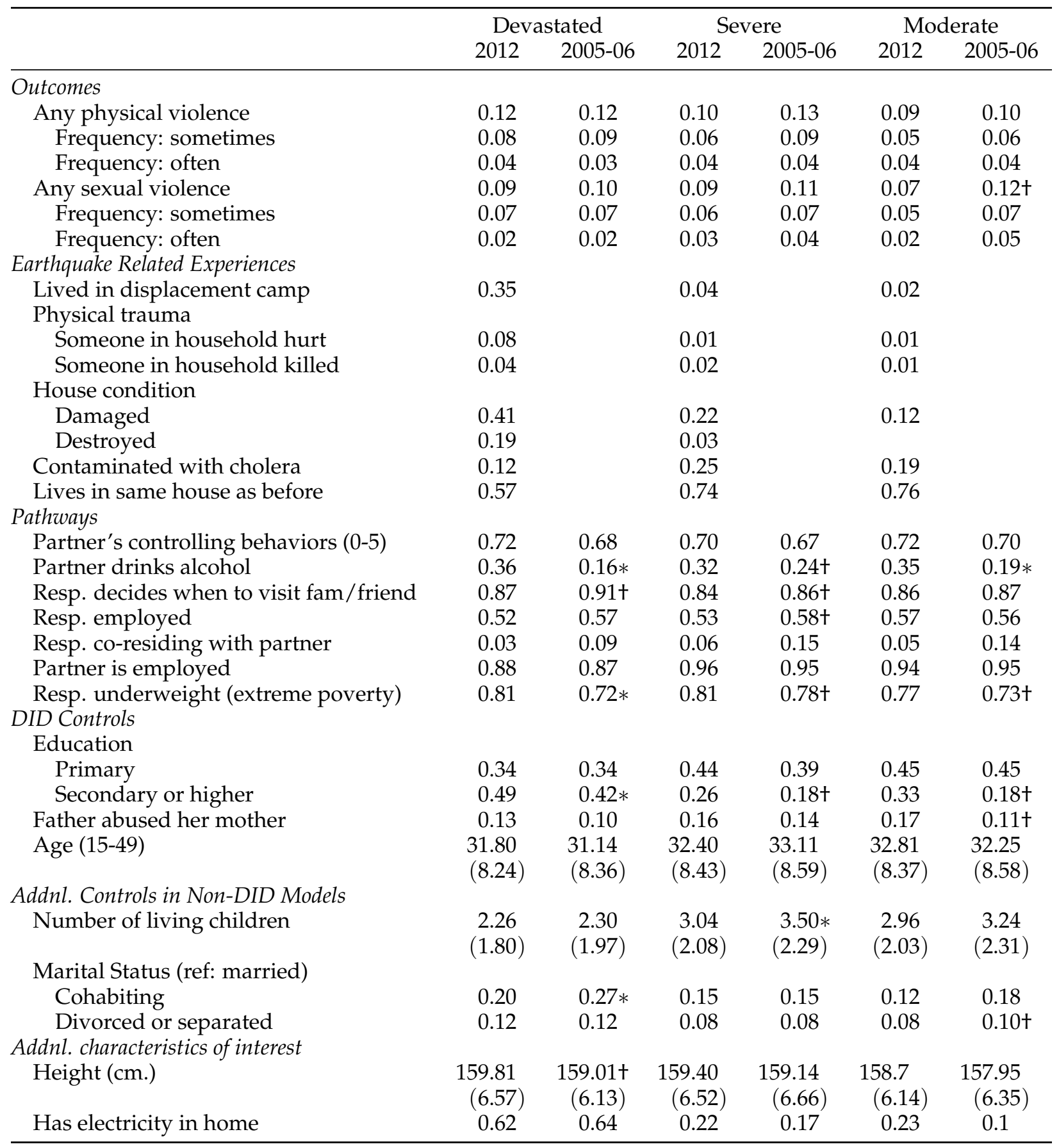

Note: Symbols denote the results of t-tests comparing proportions and means across years for each level of treatment. Descriptive statistics are calculated using DHS population weights; limited to non-widowed respondents who completed the domestic violence module. $\mathrm{N}=6,285$ in 2012; $\mathrm{N}=2,537$ in 2005/06; $\mathrm{N}=2,228$ in $2000 . * p<0.01 ;+p<0.05$ 
Table 2: Linear Probability and Multinomial Logistic Regression Estimates of the Difference in Difference in Intimate Partner Violence by Survey Wave and State-Level Earthquake Intensity

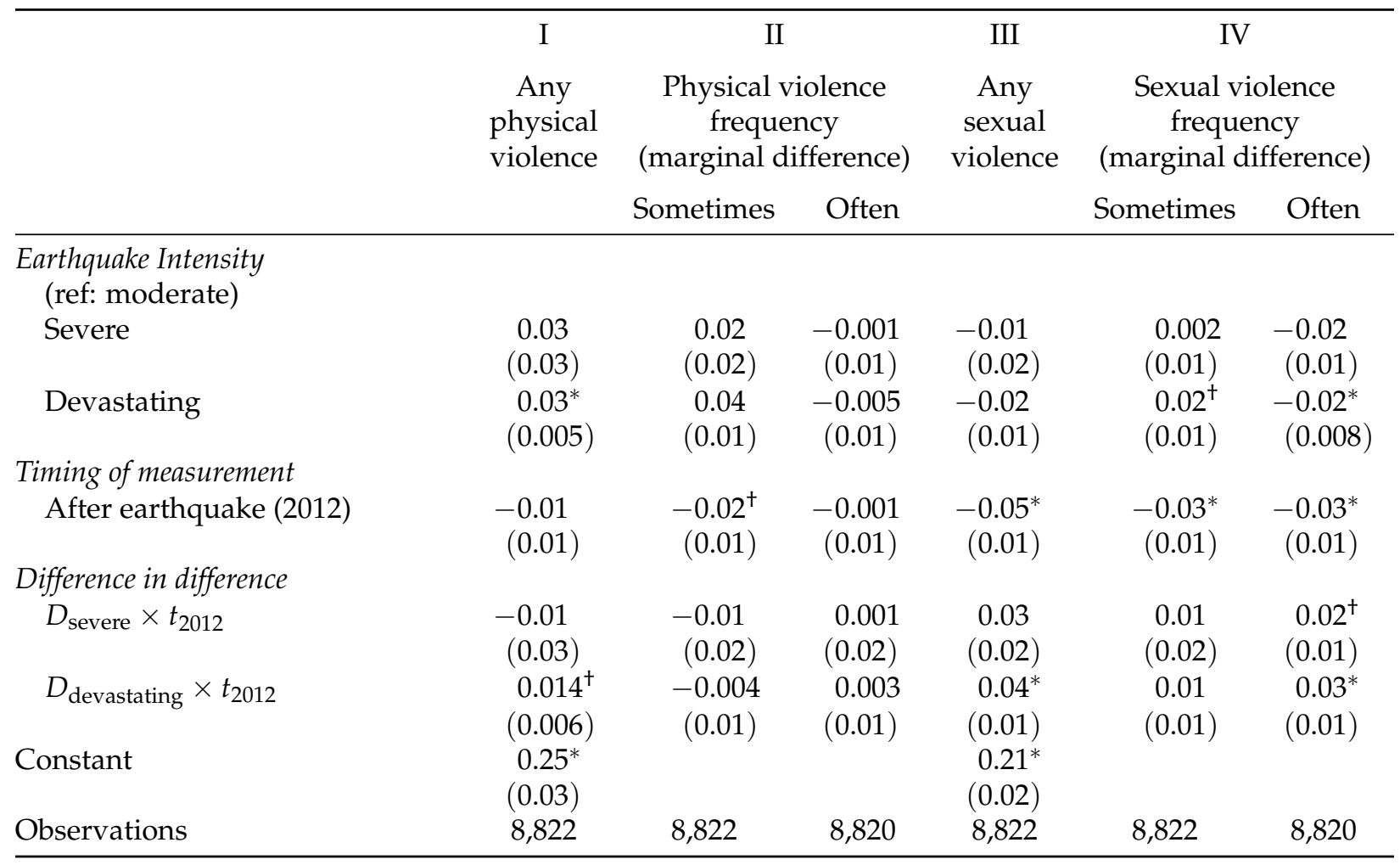

Notes: All models control for respondent's age, education, and history of family violence. The results of multinomial logistic regressions (Models II and IV) are presented as marginal effects. The marginal effects under earthquake intensity are from 2005/06; the marginal effects under timing of measurement are from 'moderate' intensity. Robust standard errors (clustered by state) in parentheses.

$* p>0.01 ;+p<0.05$.

\section{Results of Difference-in-Difference Analyses Investigating the Earthquake's Impact Pathways}

We next investigate potential pathways linking the disaster to IPV. We find mixed evidence that the earthquake heightened behaviors among respondents' partners that are simultaneously associated with coping with trauma and with the increased use of violence. Specifically, exposure to devastating earthquake intensity had no effect on partners' alcohol consumption (model V) but increased partners' number of controlling behaviors by 1.14 on a scale of 0 to 5 (model VI).

The earthquake's devastation also affected respondents' economic situations, primarily by decreasing their probability of employment by 6 percentage points (model VII), with no comparable effect on partners' employment (model VIII). Corresponding with this decrease in women's employment, earthquake devastation increased the probability that women were extremely poor by 3 percentage points, as indexed by being severely underweight (model IX). Together, the results of models VII through IX suggest that earthquake devastation may have elevated IPV by 
increasing financial stress in the home, reducing women's means of leaving abusive relationships, and undermining women's means of intrarelationship bargaining. It is also possible that partners' income but not their employment status changed as a result of the earthquake and that changes in partners' income further contributed to IPV and household poverty levels. Because the DHS do not ask questions about income, we are unable to test this latter possibility.

The results presented in model X (Table 3) suggest yet a third pathway-changes in residential arrangements: experiencing devastating earthquake intensity increased the probability of coresiding with one's partner at survey by 5 percentage points. This may have contributed to elevated levels of IPV by placing women in closer proximity to abusive partners.

Lastly, earthquake devastation affected respondents' access to their social networks. This can be seen in the 3 percentage point decrease in the probability that respondents got to decide when to visit with family or friends (model XI). Supplementary models observing whether partners permit respondents to visit with family and friends, separately, reveal that exposure to earthquake devastation decreased respondents' permission to visit with friends but not their permission to visit with family (available on request).

Given that we find significant effects of earthquake devastation on partners' controlling behaviors and the probability of respondents' employment, coresidence with partners, and participation in decisions about visiting family and friends, we next test the extent to which these pathways mediate the effects of earthquake devastation on IPV (Table 4). We first rerun our models of any physical and any sexual violence, limiting the sample to respondents' for whom no information on potential pathways is missing (column A). We then run these models again, this time adjusting for the five aforementioned indicators (column B). We find that the effect of earthquake devastation on the probability of physical IPV is fully mediated by adjusting for these pathways (model XII) but that the effects of the earthquake on sexual IPV are only partially mediated (model XIII). These latter results suggest that additional, unmeasured pathways also link earthquake exposure to sexual IPV.

\section{Results of Multivariate Analyses Observing the Effects of Earthquake Experiences on Intimate Partner Violence}

The last piece of our analysis investigates variation in the probability of IPV as it corresponds to living in a displacement camp, having a family member injured or killed, having one's home damaged or destroyed, and living in a household that has been contaminated by cholera. We take a nested model approach, beginning with a simple model that observes differences across earthquake intensity and then adding in each type of experience one at a time, finally including all four experiences. Although this portion of our analysis is descriptive, we interpret changes in the point estimates of earthquake intensity as evidence that the effects of the earthquake operated at least partially through these experiences.

Several notable patterns emerge. First, the results of models XIV and XX (Table 5) mimic the positive, monotonic effects of earthquake intensity that we observe in our DID analysis. Second, earthquake-related experiences that are significantly 


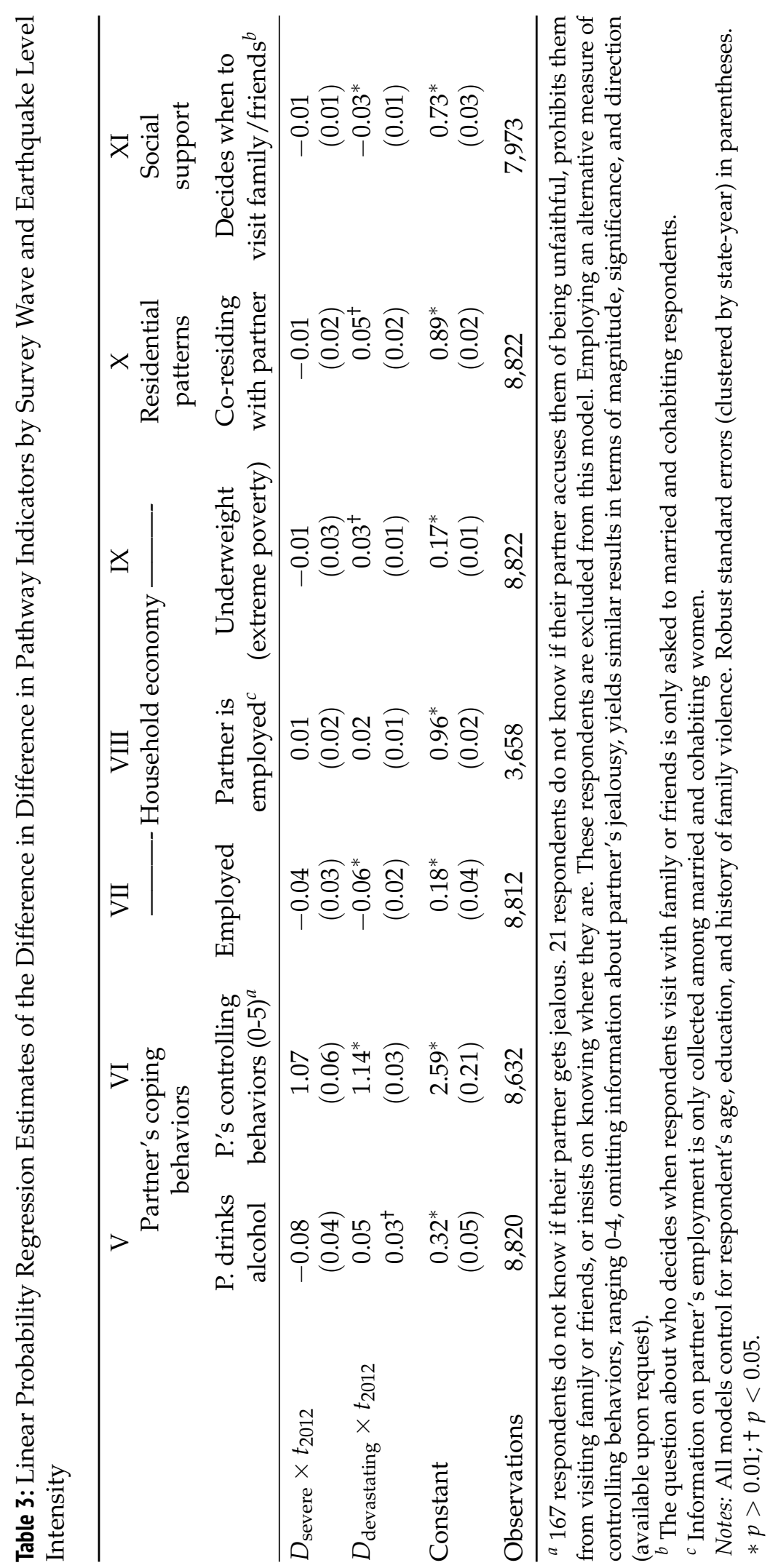


Table 4: Linear Probability Estimates of the Difference in Difference in Intimate Partner Violence by Survey Wave and State-Level Earthquake Intensity, Controlling for Significant Pathway Indicators

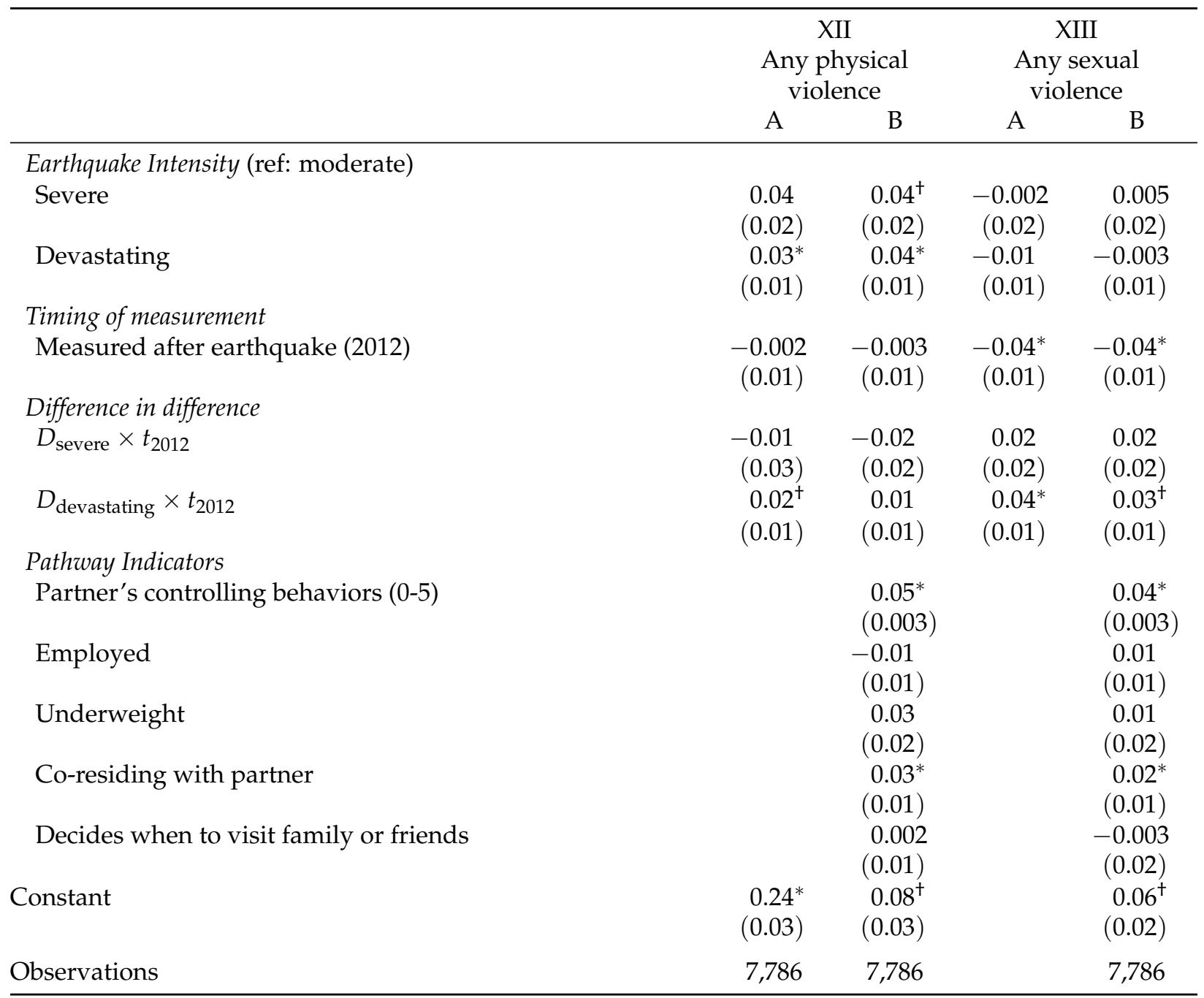

Notes: All models control for respondent's age, education, and history of family violence. Robust standard errors (clustered by state-year) in parentheses.

$* p>0.01 ;+p<0.05$.

associated with physical violence are generally also associated with sexual violence. Ever living in a displacement camp (models XV and XXI) and losing a household member (models XVI and XXII) are both positively associated with the probability of physical and sexual IPV. In addition to being stressful, both of these experiences may heighten women's vulnerability to IPV by diminishing their access to family and friends. Neither damage nor destruction to one's property has any effect in either model (XVII and XXIII). Despite these consistencies, two differences emerge. Having a family member stricken with cholera is significantly, positively associated with physical violence (model XVIII) but is not significantly associated with sexual violence (model XXIV). Having a household member wounded in the earthquake is negatively 
associated with sexual IPV (model XXV) but shares no significant association with physical IPV (model XVII).

Third, of all earthquake-related experiences, only having a household member wounded is associated with a decrease in the probability of sexual IPV (model XXII). This may be because wounded household members are themselves partners who might otherwise be abusive or because wounded household members demand care and attention that results in a different type of dynamic between respondents and their partners.

Lastly, having ever been displaced and having property damaged or destroyed both have nontrivial mediation effects on devastating earthquake intensity, whereas the same is not true for other disaster-related experiences. This suggests that displacement and property damage or destruction, but not other postdisaster situations, explain some portion of the variation in IPV across respondents residing in moderately affected, severely affected, and devastated areas of Haiti.

\section{Sensitivity Analyses}

We leverage data from the 2000 DHS to estimate alternative models that compare changes in IPV in the most devastated areas to within-intensity level preearthquake trends (measured between 2000 and 2006) (Supplementary Table 4). To calculate these alternative estimates, we interact a dummy for survey year with our treatment variable capturing future earthquake intensity. For the ease of interpretation, 2005-6 serves as the reference year. Subtracting within-treatment level changes from 2005-6 to 2012 from within-treatment level changes from 2000 to 2005-6, we find that in the devastated regions of Haiti, the probabilities of physical and sexual IPV were, respectively, $9.3(p<0.001)$ and $2(p<0.001)$ percentage points higher than in the absence of the earthquake (calculations not shown). Although the estimated differences in the severely impacted region were positive, they were not significantly different from zero.

Another counterfactual we test is the subsample of respondents residing in the state of Nord. Of all the states in Haiti, Nord is the most economically and geographically similar to Oeste. For example, it is home to the second largest city and to the second largest port in the country. Moreover, Nord was one of the states least damaged by the 2010 earthquake (Figure 1). Relying on respondents from this state as our counterfactual generates strikingly similar results to our main analyses (Supplementary Table 5), both in terms of magnitude and significance.

\section{Discussion}

In this study, we proposed and tested a sociological framework for understanding the effects of catastrophic disasters on IPV as part of a broader project of understanding how disasters affect gender and family dynamics, using the 2010 earthquake in Haiti as a test case. Our DID and descriptive analyses yield three clear findings. First, women residing in the most devastated area of the country had a higher probability of both physical and sexual forms of IPV one to two years after the 


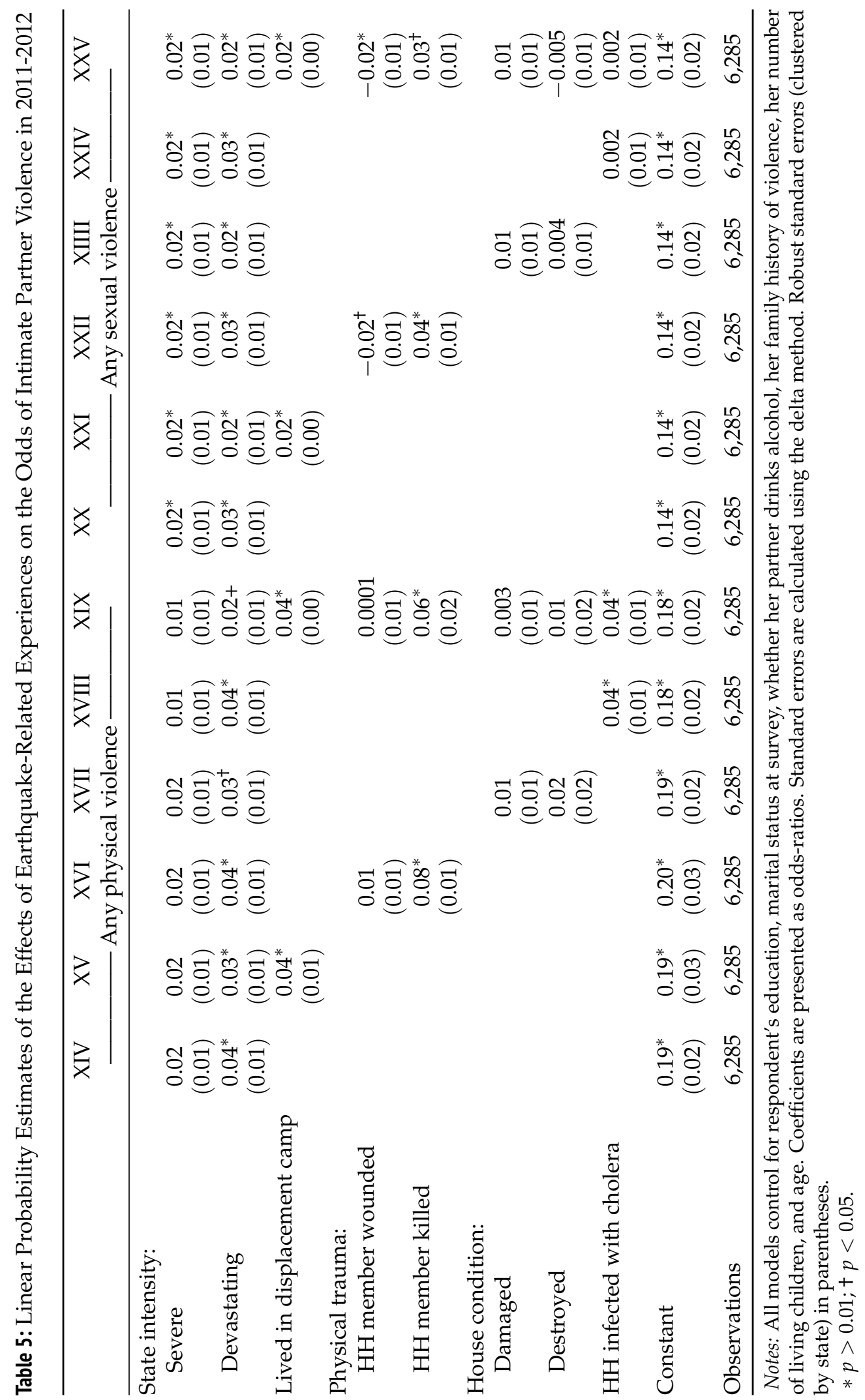


earthquake than they would have had in its absence. This is evidenced by contrasting trends in IPV—-where the earthquake had minimal damage, physical IPV fell; where the earthquake had devastating damage, physical IPV rose; and although sexual IPV fell everywhere, it fell by a rate 300 percent greater in the moderately affected areas than in the devastated areas.

Second, in line with our proposed framework, the earthquake impacted four additional dimensions of family life. These included men's controlling behaviors, which social psychological research suggests can be means of coping with trauma (Powell and Holleran Steiker 2012; Shapiro et al. 1996) that increases the risk of IPV (Antai 2011; Gage 2005). Related to these increases in men's controlling behavior, the earthquake undermined women's access to social support systems by reducing the likelihood that they decided when to visit with friends and reducing the likelihood that partners condoned such visits.

We also found that earthquake devastation undermined women's personal resource bases, namely, their employment. As our findings suggest, this reduction in women's employment increased the risk of poverty, which may have exacerbated stress and conflict between partners. Reductions in women's employment may have also made it more difficult for women to leave abusive relationships and undercut their ability to bargain with partners. Furthermore, decreases in women's employment after the earthquake's devastation may have contributed to the observed increases in coresidence. As hypothesized, these various pathways mediated the effect of earthquake devastation on IPV, though they did not fully mediate sexual IPV.

Third, we find that the probabilities of IPV were higher among women who lived in a displacement camp, who lost a household member, and whose household was affected by the cholera outbreak. For the most part, these experiences shared positive associations with both physical and sexual violence. However, only displacement and property damage or destruction mediated the effect of exposure to devastating earthquake intensity. These findings suggest that, although many stressful and traumatic earthquake-related experiences heightened IPV, only being relocated to a displacement camp explains differences observed across different levels of physical destruction caused by the earthquake. These findings also echo the results of at least two correlational studies observing IPV after Hurricane Katrina in the United States (Harville et al. 2011; Larrance et al. 2007), thus suggesting that some similarities may be found in the effects of natural disasters across disaster type and country context, though more research in this area is needed.

Because the earthquake impacted all parts of Haiti at least moderately, we have no completely unexposed sample to serve as our counterfactual. Additionally, the survey data we use were collected two years after the disaster. Both of these factors may downwardly bias our effect estimates. In fact, our alternative estimates relying on preexisting trends within regions as the counterfactual suggest that our main estimates of earthquake devastation, particularly pertaining to physical IPV, may be understated (Supplementary Table 4). Another caveat is that out-migration and mortality were also important consequences of the earthquake. Every attempt was made to ensure that the composition of pre- and postearthquake samples were comparable and to further ensure that respondent relocation did not bias our 
estimates. Moreover, even when limiting our postdisaster sample to respondents who remained in their preearthquake homes (and thus did not migrate), we still find our estimates to be nearly identical to those of our preferred models (Supplementary Table 3).

Despite certain limitations, this study's design, which takes into account changes in IPV across both space and time, is an improvement on earlier research on postdisaster IPV. Our results provide robust evidence that the 2010 earthquake had a significant and positive effect on IPV in the most devastated parts of Haiti. Furthermore, our investigation into the mechanisms by which this occurred contextualizes postdisaster IPV within broader disruptions to family life, drawing attention to the myriad ways in which women are made vulnerable to violence after devastating disasters.

\section{Notes}

1 Official estimates of cross-border migration are not available.

2 The geographic coordinates of some survey clusters are jittered to protect participants' privacy. We assume that any error introduced by this jittering is too small to bias our results.

3 In results not shown, we run all analyses observing the two original variables separately, which leads to substantively similar conclusions in terms of direction and magnitude.

4 Less than 1 percent of our 2012 sample $(n=62)$ lost a household member to cholera. We thus collapse categories of "became sick but did not die" and "died."

5 Given that the DHS measure wealth based on an index of physical assets and location, some of which may have been damaged or destroyed by the earthquake, education serves as a more accurate proxy for socioeconomic status.

6 Only one group, born between 1980 and 1985 and surveyed in the "severe" region, increased by 1.1 centimeters $<0.5$ inches) from 2006 to $2012(p<0.05)$.

\section{References}

Achecar, Maritza Molina, Nelson Ramirez, Juan Jose Polanco, Gisela Quiterio, and Maickel Garcia Ronzino. 2008. “Encuesta Sociodemografica y Sobvre VIH/SIDA En Los Bateyes Estatales de la Republica Dominicana 2007." Santo Domingo: Centro de Estudios Sociales y Demograficos and Macro International.

Achecar, Maritza Molina, Nelson Ramirez, Juan Jose Polanco, Luis H. Ochoa, Grisel Lerebours, and Brigida Garcia. 2003. "Encuesta Demografic y de Salud ENDESA 2000." Santo Domingo: Centro de Estudios Sociales y Demograficos and ORC Macro.

Antai, Diddy. 2011. “Controlling Behavior, Power Relations within Intimate Relationships and Intimate Partner Physical and Sexual Violence against Women in Nigeria." BMC Public Health 11(1):511. http: //dx . doi .org/10.1186/1471-2458-11-511.

Beydoun, Hind A., May A. Beydoun, Jay S. Kaufman, Bruce Lo, and Alan B. Zonderman. 2012. "Intimate Partner Violence against Adult Women and Its Association with Major Depressive Disorder, Depressive Symptoms and Postpartum Depression: A Systematic Review and Meta-analysis." Social Science and Medicine 75(6):959-75. http://dx.doi. org/10.1016/j. socscimed.2012.04.025. 
Bott, Sarah, Alessandra Guedes, Mary Goodwin, and Jennifer Adams Mendoza. 2012. "Violence against Women in Latin America and the Caribbean: A Comparative Analysis of Population-Based Data from 12 Countries." Washington, DC: Pan American Health Organization.

Bruckner, Tim A. and Jenna Nobles. 2013. “Intrauterine Stress and Male Cohort Quality: The Case of September 11, 2001." Social Science and Medicine 76:107-14. http://dx. doi .org/ $10.1016 / \mathrm{j}$.socscimed.2012.10.012.

Catalano, Shannan M. 2012. “Intimate Partner Violence, 1993-2010.” Washington, DC: U.S. Department of Justice.

Cayemittes, Michel, Marie Florencia Placide, Bernard Barrere, and Blaise Severe. 2001. "Enque?te Mortaliteì, Morbiditeì et Utilisation des Services EMMUS-III Haiti 2000." Calverton, MD: MinisteÌre de la Santeì Publique et de la Population (MSPP).

Cayemittes, Michel, Marie Florencia Placide, Soumaila Mariko, Bernard Barrere, Blaise Severe, and Canez Alexandre. 2007. "Enquete Mortalite, Morbidite et Utilisation des Services Emmus-IB Haiti 2005-2006. . Calverton, MD: Institut Haitien de l'Enfance (IHE) Peìtion-Ville, Haiti et Macro International Inc.

Clemens, Petra, Jennifer R. Hietala, Mamie J. Rytter, Robin A. Schmidt, and Dona J. Reese. 1999. "Risk of Domestic Violence after Flood Impact: Effects of Social Support, Age, and History of Domestic Violence." Applied Behavioral Science Review 7(2):199-206. http: //dx.doi.org/10.1016/S1068-8595(00)80020-3.

Crowne, Sarah Shea, Hee-Soon Juon, Margaret Ensminger, Lori Burrell, Elizabeth McFarlane, and Anne Duggan. 2011. "Concurrent and Long-Term Impact of Intimate Partner Violence on Employment Stability." Journal of Interpersonal Violence 26(6):1282-304. http: //dx.doi.org/10.1177/0886260510368160.

Doocy, Shannon, Megan Cherewick, and Thomas Kirsch. 2013. "Mortality Following the Haitian Earthquake of 2010: A Stratified Cluster Survey." Population Health Metrics 11(5):5-13.

Farmer, Paul. 2011. Haiti after the Earthquake. New York: Public Affairs.

Ferris, Elizabeth. 2014. "Recurrent Acute Disasters, Crisis Migration: Haiti Has Had It All." Pp. 77-96 in Migration and Humanitarian Crisis: Causes, Consequences, and Responses, edited by Susan F. Martin, Sanjula Veerasinghe, and Abbie Taylor. New York: Routledge.

Fothergill, A. 1999. "An Exploratory Study of Woman Battering in the Grand Forks Flood Disaster: Implications for Community Responses and Policies." International Journal of Mass Emergencies and Disasters 17(1):79-98.

Fox, Greer Litton, Michael L. Benson, Alfred A. DeMaris, and Judy Van Wyk. 2002. "Economic Distress and Intimate Violence: Testing Family Stress and Resources Theories." Journal of Marriage and Family 64(3):793-807. http: //dx . doi .org/10.1111/j .1741-3737. 2002.00793.x.

Frankenberg, Elizabeth, Jed Friedman, Thomas Gillespie, Nicholas Ingwersen, Robert Pynoos, Iip Umar AMa Rifai, Bondan Sikoki, Alan Steinberg, Cecep Sumantri, Wayan Suriastini, and Duncan Thomas. 2008. "Mental Health in Sumatra after the Tsunami." American Journal of Public Health 98(9):1671-77. http: //dx. doi .org/10.2105/AJPH . 2007 .120915.

Frankenberg, Elizabeth, Bondan Sikoki, Cecep Sumantri, Wayan Suriastini, and Duncan Thomas. 2013. "Education, Vulnerability, and Resilience after a Natural Disaster." Ecology and Society 18(2):189-201.

Fuller, Sarah C. 2014. "The Effect of Prenatal Natural Disaster Exposure on School Outcomes." Demography 51(4):1501-25. http://dx . doi .org/10.1007/s13524-014-0310-0. 
Fulu, Emma. 2007. "Gender, Vulnerability, and the Experts: Responding to the Maldives Tsunami." Development and Change 38(5):843-64. http://dx. doi .org/10.1111/j. $1467-7660.2007 .00436 . x$.

Gage, Anastasia J. 2005. “Women's Experience of Intimate Partner Violence in Haiti." Social Science and Medicine 61(2):343-64. http://dx.doi .org/10.1016/j . socscimed . 2004 .11. 078.

Gelman, Andrew and Jennifer Hill. 2007. Data Analysis Using Regression and Multilevel/Hierarchical Models. Cambridge: Cambridge University Press.

Goode, William J. 1971. "Force and Violence in the Family." Journal of Marriage and Family 33(4):624-36. http://dx.doi.org/10.2307/349435.

Harville, Emily W., Catherine A. Taylor, Helen Tesfai, Xu Xiong, and Pierre Buekens. 2011. "Experience of Hurricane Katrina and Reported Intimate Partner Violence." Journal of Interpersonal Violence 26(4):833-45.

Kalmuss, Debra S. and Murray A. Straus. 1982. "Wife's Marital Dependency and Wife Abuse." Journal of Marriage and Family 44(2):277-86. http: //dx . doi .org/10 . 2307/351538.

Katz, Jonathan. 2013. The Big Truck That Went By: How the World Came to Save Haiti and Left Behind a Disaster. New York: Palgrave Macmillan.

Klinenberg, Eric. 2002. Heat Wave: A Social Autopsy of Disaster in Chicago. Chicago: University of Chicago Press.

Kolbe, Athena R. 2010. "Mortality, Crime and Access to Basic Needs before and after the Haiti Earthquake: A Random Survey of Port-au-Prince Households." Medicine, Conflict, and Survival 26(4):281-97. http: //dx . doi .org/10.1080/13623699.2010.535279.

Larrance, Ryan, Michael Anastario, and Lynn Lawry. 2007. "Health Status among Internally Displaced Persons in Louisiana and Mississippi Travel Trailer Parks." Annals of Emergency Medicine 49(5):590-601.

Lu, Xin. 2012. "Predictability of Population Displacement after the 2010 Haiti Earthquake." Proceedings of the National Academy of Sciences of the United States of America 109(29):1157681. http://dx.doi.org/10.1073/pnas.1203882109.

MacDonald, Rhona. 2005. "How Women Were Affected by the Tsunami: A Perspective from Oxfam." PLoS Medicine 2(6):e178.

Murray, Royce Bernstein and Sarah Petrin Williamson. 2011. "Migration as a Tool for Disaster Recovery: A Case Study on U.S. Policy Options for Post-earthquake Haiti." Working paper, Center for Global Development.

Palermo, Tia, Jennifer Bleck, and Amber Peterman. 2014. “Tip of the Iceberg: Reporting and Gender-Based Violence in Developing Countries." American Journal of Epidemiology 179(5):602-12. http://dx.doi.org/10.1093/aje/kwt295.

Piarroux, Renaud, Robert Barrais, Benoît Faucher, Rachel Haus, Martine Piarroux, Jean Gaudart, Roc Magloire, and Didier Raoult. 2011. "Understanding the Cholera Epidemic, Haiti." Emerging Infectious Diseases 17(7):1161-68. http://dx . doi .org/10.3201/ eid1707.110059.

Pierotti, Rachael S. 2013. "Increasing Rejection of Intimate Partner Violence Evidence of Global Cultural Diffusion." American Sociological Review 78(2):240-65. http://dx.doi . org/10.1177/0003122413480363.

Powell, Tara and Lori K. Holleran Steiker. 2012. “Working with Children and Families Who Have Survived Natural Disasters: Exploring Substance Abuse and Other Risk Factors." Journal of Social Work Practice in the Addictions 12(2):209-14. http://dx. doi. org/10.1080/1533256X.2012.672129. 
Shapiro, Deane H., Jr., Carolyn E. Schwartz, and John A. Astin. 1996. “Controlling Ourselves, Controlling Our World: Psychology's Role in Understanding Positive and Negative Consequences of Seeking and Gaining Control." American Psychologist 51(12):1213-30. http://dx.doi.org/10.1037/0003-066X.51.12.1213.

Siegel, Judith M., L. B. Bourque, and K. I. Shoaf. 1999. “Victimization after a Natural Disaster: Social Disorganization or Community Cohesion?" International Journal of Mass Emergencies and Disasters 17(3):265-94.

World Bank. 2014. "Indicators: Poverty Headcount Ratio at \$1.90 a Day (2011 PPP) (\% of Population), 2012." http://databank . worldbank.org/data/reports . aspx? source $\$=$ $\$ 2\{\&\}$ Topic $\$=\$ 11\{\#\}$.

Acknowledgements: This research was made possible with the generous support of the National Science Foundation (grant 2011117755) and the William and Flora Hewlett Foundation/International Institute for Education (grant 2012-7263). Background support was also provided by the grant "Team 1000+ Saving Brain: Economic Impact of Poverty-Related Risk Factors for Cognitive Development and Human Capital" 0072-03 provided to the grantee, the Trustees of the University of Pennsylvania, by Grand Challenges Canada. We are grateful to Paula England, Jere Behrman, and Dalton Conley for their invaluable feedback on this research. We are also grateful to Himanshu Mistry and New York University's Data Service Studio for assisting us in our spatial analyses.

Abigail Weitzman: Population Studies Center, University of Michigan.

E-mail: aweitzma@umich.edu.

Julia Andrea Behrman: New York University. E-mail: Jab965@nyu.edu. 